\title{
Thrombokinetics in patients with rheumatoid arthritis treated with D-penicillamine
}

\author{
D. THOMAS,${ }^{1}$ A. S. GALLUS,${ }^{2}$ P. M. B ROOKS,${ }^{1}$ R. TAMPI,${ }^{2}{ }^{*}$ R. GEDDES,${ }^{1}$ \\ A N D W. HILL' \\ From the ${ }^{1}$ Departments of Medicine and ${ }^{2}$ Haematology, Flinders Medical Centre, Bedford Park, South \\ Australia 5042, and Repatriation General Hospital, Daw Park, South Australia 5041
}

SUMMARY The mechanism of D-penicillamine induced thrombocytopenia in rheumatoid arthritis was investigated by measuring platelet life-span and platelet production rate in 2 groups of rheumatoid arthritis patients treated with $250-750 \mathrm{mg} /$ day D-penicillamine, 14 with a normal platelet count and 9 with thrombocytopenia (platelet count 50-130 $\times 10^{9} / 1$ ). Age matched control patients not treated with D-penicillamine included 14 with rheumatoid arthritis and 9 with osteoarthritis. The platelet life-span was normal, but platelet production rate was significantly reduced in the thrombocytopenic patients, suggesting that D-penicillamine causes thrombocytopenia through bone marrow suppression.

The haematological side effects of D-penicillamine treatment are well recognised and potentially serious. They include marrow aplasia, which has contributed significantly to reported fatalities, ${ }^{1}$ neutropenia, ${ }^{2-4}$ an isolated case of haemolytic anaemia, ${ }^{5}$ and thrombocytopenia.

Thrombocytopenia is the commonest haematological side effect, with a reported incidence of $12-27 \%$ in patients treated with D-penicillamine for rheumatoid athritis. ${ }^{267}$ The mechanism is unknown, but 2 major processes may be involved. One is drug-induced failure of platelet productior and the other is accelerated peripheral destruction through a drug-dependent immune-mediated process. There is some clinical evidence which suggests that thrombocytopenia during D-penicillamine treatment may be an early manifestation of bonemarrow failure. Thus Kay ${ }^{1}$ found that a fall in platelet count or neutrophil count had been present for some months before the development of fatal bone marrow aplasia in 7 of 10 patients who developed this complication. Marrow aplasia caused 10 of the 18 deaths in her review. We are not aware of any reports which

Accepted for publication 18 July 1983.

Correspondence to Professor P. M. Brooks, Department of Rheumatology, Royal North Shore Hospital, St Leonards, New South Wales 2067, Australia.

${ }^{*}$ Present Address: Department of Haematology, Royal Perth Hospital, Western Australia. demonstrate the presence of drug-dependent antiplatelet antibodies during thrombocytopenia caused by $D$-penicillamine.

The standard, simple, haematological techniques of bone-marrow aspiration and biopsy are insensitive to early marrow failure or mildly increased platelet consumption. Thrombokinetic studies are more sensitive and have been used in rheumatology to demonstrate increased platelet production which returned to normal during steroid therapy in patients with giant cell arthritis. ${ }^{8}$ We have measured platelet survival in patients with rheumatoid arthritis in order to investigate the mechanism of D-penicillamine induced thrombocytopenia.

\section{Materials and methods}

Thirty-two platelet survival studies were performed on 27 patients with definite or classical rheumatoid arthritis, the patients falling into 3 groups (Table 1):

Group $A$. Fourteen studies on patients not treated with D-penicillamine who had a normal platelet count.

Group B. Nine studies on patients treated with D-penicillamine who had a normal platelet count (4 were repeat studies on patients originally studied in Group A).

Group C. Nine studies on patients who developed a platelet count below $150 \times 10^{9} /$ Litre during treatment with D-penicillamine (one was a repeat study of a patient previously studied in Group B). 
Table 1 Patient classification

\begin{tabular}{|c|c|c|c|c|}
\hline Groups & No. & Study & $\begin{array}{l}\text { Age (years), } \\
\text { mean and range }\end{array}$ & $\begin{array}{l}\text { Duration of disease (years), } \\
\text { mean and range }\end{array}$ \\
\hline $\mathbf{A}$ & 14 & Patients with RA not taking D-penicillamine & $58(40-69)$ & $13 \cdot 1(0 \cdot 25-35)$ \\
\hline B & $9^{*}$ & $\begin{array}{l}\text { Patients with RA taking D-penicillamine, } \\
\text { nonthrombocytopenic }\end{array}$ & $63(40-75)$ & \\
\hline C & $9+$ & $\begin{array}{l}\text { RA patients taking D-penicillamine with } \\
\text { platelet count less than } 150 \times 10^{\circ} / 1\end{array}$ & $63(52-76)$ & $9 \cdot 6(1-20)$ \\
\hline D & 9 & $\begin{array}{l}\text { Hospital controls with normal platelet } \\
\text { count }\end{array}$ & $54(27-77)$ & - \\
\hline $\mathbf{E}$ & 3 & $\begin{array}{l}\text { Two patients with ITP, one with Felty's } \\
\text { syndrome }\end{array}$ & $70(67-75)$ & - \\
\hline
\end{tabular}

* Four patients were also studied in Group A.

† One patient was also studied in group B.

ITP = idiopathic thrombocytopenic purpura.

The mean age of these patients and the known duration of rheumatoid arthritis are shown in Table 1.

In addition platelet survival was measured in 9 age-matched hospital controls without rheumatoid arthritis who had a normal platelet count and did not have any illness known to influence platelet kinetics. These patients had osteoarthritis and had been in hospital for a variety of minor orthopaedic procedures. Lastly, platelet survival studies were carried out on 3 patients with non-drug related thrombocytopenia: 2 with idiopathic thrombocytopenia purpura, and one with Felty's syndrome (Table 1).

The platelet count was measured with Hemalog$8 / 90$ (Technicon) at 2- to 4-week intervals in all patients treated with D-penicillamine in the rheumatology outpatient clinic, which allowed the selection of patients for study in group $\mathrm{C}$ as soon as possible after they developed thrombocytopenia.

Table 2 shows the D-penicillamine dose and platelet count in the group $C$ patients during the 3 months before thrombocytopenia was detected, the minimum platelet count and D-penicillamine dose taken when this was observed, the D-penicillamine dose and platelet count during platelet survival study, the time for the platelet count to return to within the normal range after dose-reduction or stopping D-penicillamine, and the D-penicillamine dose and average platelet count during the 3 months after the thrombocytopenic episode.

It will be noted that 7 of the group $C$ patients continued to take D-penicillamine ( 2 at a reduced dose) despite thrombocytopenia throughout the platelet survival study, while D-penicillamine was temporarily stopped before the study began in 2 patients ( 8 and 9$)$.

D-penicillamine was permanently discontinued before or after platelet survival study in 3 group C patients $(4,7$, and 9$)$ with return of the platelet count to normal (4 and 7) or just below the normal range (9). It is of interest that the platelet count also returned to within the normal range despite continued D-penicillamine treatment in the other 6 group $C$ patients, 2 of whom resumed their previous dose ( 1 and 5), while the others were kept at a reduced maintenance dose of D-penicillamine.

Platelet survival was measured by the ${ }^{51} \mathrm{Cr}$-sodium chromate labelling technique recommended by the International Committee for Standardization in Haemotology ${ }^{9}$ after the patients had had the procedure explained to them and had signed the appropriate consent form. The study was approved by the institutional ethics committee. Autologous platelets were used in all studies except on the 2 patients with idiopathic thrombocytopenic purpura, for whom $\mathrm{ABO}$ and Rh-compatible HBs antigen-negative platelets were obtained from volunteer Red Cross blood donors.

${ }^{51} \mathrm{Cr}$-labelled platelets were prepared as follows. Approximately $350 \mathrm{ml}$ of blood was collected by gravity into the first bag of a triple collection pack containing $67.5 \mathrm{ml}$ of acid citrate dextrose (ACD) (Fenwall/Travenol). After centrifugation at $370 \mathrm{~g}$ for 15 minutes in a Sorvall GP RC-3 automatic refrigerated centrifuge, platelet rich plasma (PRP) was transferred by gravity to the second bag containing $25 \mathrm{ml}$ of ACD. PRP was then centrifuged at $1700 \mathrm{~g}$ for 15 minutes to prepare a platelet pellet, which was resuspended in $5 \mathrm{ml}$ of platelet-poor plasma (PPP). The resulting platelet concentration was incubated with $250 \mu \mathrm{Ci}\left(9.25 \times 10^{9}\right.$ Bequerels) preservative free ${ }^{51} \mathrm{Cr}$-sodium chromate solution obtained at a specific activity of $1 \mu \mathrm{Ci} / \mu$ l from the Radiochemical Centre, Amersham, England, then washed once with PPP to remove unbound ${ }^{51} \mathrm{Cr}$-sodium chromate, and finally centrifuged at $170 \mathrm{~g}$ for 10 minutes to remove any contamination by ${ }^{51} \mathrm{Cr}$-labelled red cells.

The packed red cells were then returned to the 


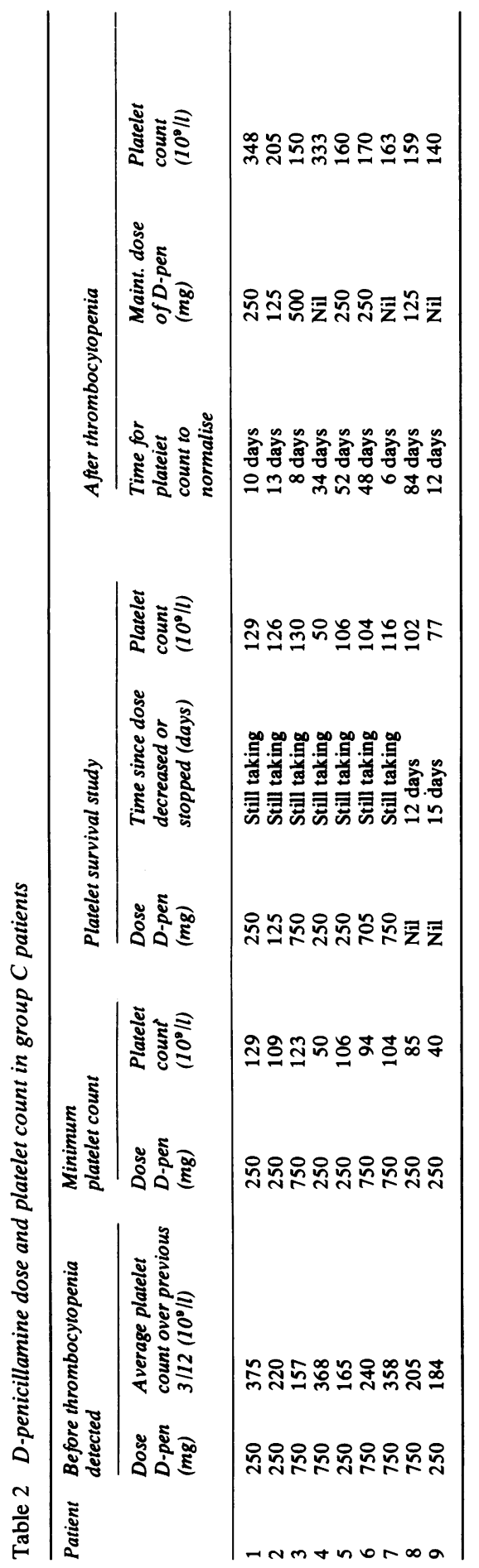

patient. The ${ }^{51} \mathrm{Cr}$-labelled platelets were injected after the ir volume had been noted and a $1 \mathrm{ml}$ aliquot retained to measure the amount of ${ }^{51} \mathrm{Cr}$-bound to platelets, red cells, and plasma proteins. ${ }^{9}$

The percentage of radioactivity bound to red cells was in every case less than $5 \%$. The time of injection of radiolabelled platelets was recorded, and blood samples were collected for measuring circulating radioactivity at 2 hours and 24 hours after injection of ${ }^{51} \mathrm{Cr}$-labelled platelets, and then daily for 7 days. For each sample $5 \mathrm{ml}$ of venous blood was taken into ethylene diaminotetra-acetate (EDTA), the platelet count was measured, and 2 aliquots of $2 \mathrm{ml}$ whole blood were prepared by lysis with sodium dodecyl sulphate for counting in a scintillation counter (Searle 1195). Lysed samples and standards were counted together at the end of each platelet survival study.

The following calculations were made: linear estimate of platelet survival (days), obtained by fitting a linear decay function to the observed level of circulating radioactivity in each blood sample and extrapolating this to zero activity on the time axis; platelet recovery, representing the proportion of injected platelet-bound radioactivity recovered from circulating blood when the platelet survival curve was extrapolated back to the time of injection, $\mathrm{t}_{0}$; and platelet production rate, the number of platelets produced per litre of blood per day, calculated from platelet life-span, platelet recovery, and the circulating platelet count. For the calculation of platelet recovery the blood volume was assumed to be $70 \mathrm{ml} / \mathrm{kg}$.

Similar calculations were also made after fitting the platelet survival data to an exponential decay model, but they are not reported here as they led to identical conclusions

DATA ANALYSIS

Standard statistical methods were used. Mean values \pm standard deviation of mean (SD) are reported. Mean values for platelet count, platelet recovery, platelet life-span, and platelet production rate were compared between patient groups by the unpaired Student's $t$-test after logarithmic transformation to normalise the data (for platelet count and platelet production rate). Linear regressions were computed on a hand-held programmable HP-67 calculator.

\section{Results}

The mean platelet count, platelet recovery, and platelet survival, and the calculated daily platelet production rate found in the 4 study groups are summarised in Table 3 . The mean platelet count during the platelet survival study was significantly lower in group $C$ patients $\left(107 \pm 25 \times 10^{9} / 1\right)$ than in groups 
Table 3 Platelet count, platelet recovery, platelet survival, and calculated platelet production rate in the 4 study groups (mean \pm standard deviation)

\begin{tabular}{llllll}
\hline Group & Number & $\begin{array}{l}\text { Platelet count at } \\
\text { time of study }\left(10^{\circ} / l\right)\end{array}$ & $\begin{array}{l}\text { Platelet } \\
\text { recovery (\%) }\end{array}$ & $\begin{array}{l}\text { Platelet survival (days) } \\
\text { (linear analysis) }\end{array}$ & $\begin{array}{l}\text { Platelet production } \\
\text { rate }\left(10^{\circ} / l /\right)\end{array}$ \\
\hline A & 14 & $355 \pm 106$ & $67 \pm 14$ & $8 \cdot 7 \pm 0 \cdot 9$ & $61 \pm 34$ \\
B & 9 & $240 \pm 31$ & $71 \pm 14$ & $8 \cdot 9 \pm 1 \cdot 1$ & $40 \pm 11$ \\
C & 9 & $107 \pm 27$ & $72 \pm 15$ & $8 \cdot 0 \pm 1 \cdot 2$ & $20 \pm 8$ \\
D & 9 & $258 \pm 58$ & $67 \pm 12$ & $8 \cdot 6 \pm 1 \cdot 1$ & $44 \pm 6$ \\
\hline
\end{tabular}

$\mathrm{A}, \mathrm{B}$, or $\mathrm{D}$ ( $\mathrm{p}<0.001$ for all 3 comparisons). In addition the mean platelet count was significantly higher in group $A$ than in group $B$ and $D(p<0 \cdot 05)$. Repeat platelet counts done at the end of the platelet survival study were available in 7 of 9 group $C$ patients and showed persisting thrombocytopenia (coefficient of variation $=6 \%$ ), implying a steady state of platelet production and destruction in these patients throughout the measurement period.

Platelet recovery and platelet survival were similar in the 4 study groups (Table 3 ). The calculated daily platelet production rate was significantly lower in group $C$ than in groups $A, B$, or $D(p<0.005$ for all 3 comparisons) (Table 3 ). Platelet production rate in D-penicillamime treated patients without thrombocytopenia (group B) was similar to that in group D controls, but significantly less than that of untreated patients with rheumatoid arthritis (group A) $(p<0.02)$. Platelet survival in the 2 patients with idiopathic thrombocytopenic purpura was markedly reduced, and both platelet recovery and platelet survival were reduced in the patient with Felty's syndrome, as expected for these conditions.

\section{Discussion}

These data suggest that thrombocytopenia associated with D-penicillamine treatment was due to a reduced platelet production rate in the patients studied. Thus the mean platelet survival time measured during the thrombocytopenia episode in group $\mathrm{C}$ patients was not significantly different from that in control patients with osteoarthritis or in patients with rheumatoid arthritis and a normal platelet count (with or without D-penicillamine treatment). Further, platelet survival was within the normal range reported from previous studies. ${ }^{10}$ On the other hand the calculated daily platelet production rate was markedly reduced when $D$-penicillamine treatment was complicated by thrombocytopenia.

Drug-dependent antibody-mediated platelet destruction which had ceased by the time of platelet survival study seems to have been ruled out as a cause of the thrombocytopenia, as 7 of the 9 thrombocytopenic patients were studied while they were still taking D-penicillamine. The predicted results in the 3 group $E$ patients (with immune thrombocytopenia or Felty's syndrome) showed that our platelet survival method could detect increased platelet destruction.

The reduced platelet production rate during thrombocytopenia implies that D-penicillamine caused this complication through bone marrow suppression. It is therefore of great interest that treatment could be resumed without return of thrombocytopenia in most of these patients, suggesting that some other, transient, unknown aetiological factor may also have been involved. Whether the patients who developed thrombocy topenia will now be at high risk of further D-penicillamine induced marrow suppression is not known.

The observation that D-penicillamine treatment uncomplicated by thrombocytopenia (group B) was associated with a significant reduction in platelet count and platelet production rate from that seen in untreated patients with rheumatoid arthritis (group A) probably reflects suppression of disease activity by $D$-penicillamine, as results in the group $B$ patients were similar to those seen in group D controls. Increased platelet production is commonly seen in inflammatory disorders, ${ }^{10}$ and active rheumatoid arthritis may be associated with thrombocytosis. ${ }^{11}$

Although the mechanism remains unclear, this study strongly suggests that D-penicillamine causes thrombocytopenia by suppressing platelet production. The platelet production rate is a sensitive indicator of bone marrow suppression, and it is often the last haematological parameter to return to normal after an episode of marrow hypoplasia. ${ }^{12}$ D-penicillamine can cause marrow hypoplasia or aplasia, ${ }^{17}$ and it is possible that the thrombocytopenia associated with D-penicillamine treatment reflects general marrow toxicity rather than a specific effect on platelet precursors. It would therefore seem wise carefully to monitor patients who continue to take D-penicillamine after an episode of thrombocytopenia. 


\section{References}

1 Kay A G L. Myelotoxicity of D-penicillamine. Ann Rheum Dis 1979; 38: 232-6.

2 Balme H W, Huskisson E C. Side effects of penicillamine other than nephropathy and their management, In: Munthe E, ed. Penicillamine research in rheumatoid disease. Oslo: Fabritus and Sønner, 1976: 250-2.

3 Golding J R, Day A T, Tomlinson M R, Brown R M, Hassan M O, Landstaff S R. Rheumatoid arthritis treated with small doses of penicillamine. Proc $R$ Soc Med 1977; 70: (suppl 3): 131-3.

4 Halverson P B, Kozin F, Bernhard G C, Goldman A L. Toxicity of penicillamine. A serious limitation to therapy in rheumatoid arthritis. JAMA 1978; 240: 1870-1.

5 Harrison E E, Hickman J W. D-penicillamine and haemolytic anaemia. Lancet 1976; i: 38 .
6 Andrews F M, Camp A V, Day A T, et al. Controlled trial of D(-)penicillamine in severe rheumatoid arthritis. Lancet 1973; i: 275-80.

7 Lyle W H. Penicillamine. Clin Rheum Dis 1979; 5: 569-601.

8 Bergstrom A L, Bengtsson B A, Ollsson L B, Malmvall B E, Kutti J. Thrombokinetics in giant cell arteritis with special reference to corticosteroid. Ann Rheum Dis 1979; 38: 244-5.

9 International Committee for Standardization in Haematology. Recommended methods of isotope platelet survival studies. Blood 1977; 50: 1137-44.

10 Harker L A, Finch C A. Thrombokinetics in man.J Clin Invest 1969; 48: 963-74.

11 Hutchinson R M, Davis P, Jayson M I V. Thrombocytosis in rheumatoid arthritis. Ann Rheum Dis 1976; 35: 138-42.

12 Williams W J, Beutler E, Ersley A J, Rundles R W, eds. Hematology. 2nd ed. New York: McGraw Hill, 1977: 226. 